\title{
Natural water storage and aquifer recharge assessment in Brazilian savanna wetland using unmanned aerial vehicle and geophysical survey
}

\author{
Lucas Furlan ${ }^{1}$, Vania Rosolen ${ }^{2}$, Jepherson Sales $^{3}$, Cesar Moreira ${ }^{2}$, Manuel Ferreira ${ }^{4}$, \\ Guilherme Bueno ${ }^{3}$, Carla Coelho ${ }^{2}$, and Stéphane Mounier ${ }^{5}$ \\ ${ }^{1}$ Universidade Estadual Paulista Julio de Mesquita Filho Instituto de Biociencias Campus \\ de Rio Claro \\ ${ }^{2}$ Universidade Estadual Paulista Julio de Mesquita Filho \\ ${ }^{3}$ Universidade Federal Goiás \\ ${ }^{4}$ Universidade Federal de Goias \\ ${ }^{5}$ Universite de Toulon
}

May 5, 2020

\begin{abstract}
Human pressure on the water resources provided by natural wetlands has intensified in Brazil due to an increase in agricultural land equipped with irrigation. However, the amount of water stored in these areas, and its contribution to aquifer recharge is unknown. The objectives of this study were to determine the amount of water that can be retained in a natural wetland surrounded by farmland and to propose a model of groundwater recharge. We used remote sensing techniques involving Unmanned Aerial Vehicle (UAV) to map the area and highlight the wetland internal morphology, using RGB orthomosaic and its respective digital surface model. According to the topography of the study area, three compartments were defined. Compartment 1, corresponding to the external border of the wetland, can store $313,121.00 \mathrm{~m}^{3}$ of water; compartment 2 and 3 can store $85,923.20 \mathrm{~m}^{3}$ and $17,952.10 \mathrm{~m}^{3}$, respectively. The $2 \mathrm{D}$ inversion and a pseudo-3D model produced from Electrical Resistivity Tomography (ETR) data were used to visualize the subsurface geologic structure and hydrologic flow paths. Our results showed the direct interactions between groundwater $(\mathrm{GW})$ and surface water $(\mathrm{SW})$ in the center of the wetland (compartment 3), which constitutes the aquifer recharge zone with vertical infiltration. As the depth increases, infiltration and water flow deviate laterally in the southwest and northeast direction. The wetland is characterized as an unconfined aquifer that plays an important role in the hydrogeological dynamics of the catchment. Remotely sensed very high-resolution images allied with geophysical techniques allowed complete surface and subsurface imaging and offered visual tools that contributed to understanding the hydrodynamics of the wetland.
\end{abstract}

\section{Introduction}

Worldwide, 324 million hectares of land, which contribute $40 \%$ of the total food production, are equipped for irrigation (FAO, 2016). At a global scale, average annual water consumption by irrigation is 7,700 m3 per hectare. In Brazil, irrigation's water uptake is approximately $1000 \mathrm{~m} 3 / \mathrm{s}$, characterizing the major consumption in the territory. That quantity is distributed through irrigations systems covering 7 million ha with potential to expand by $43.3 \%$ (ANA, 2017). In the countryside, rivers and small dams are the major sources of irrigation, despite the substantial volumetric impact on water resources during the dry season. Considering that both urban and rural water supplies are provided by superficial water, scarcity has been a critical concern. For example, in the biennium 2014-2015, the reservoirs of São Paulo metropolitan region were reduced to single-digit percentages, leading to a profound water crisis (Millington, 2018). 
Almost $20 \%$ of the Brazilian territory is covered by wetlands, and their distribution has been dramatically reduced by land conversion, thus affecting their natural water storage and ecological functions (Junk et al., 2013; Rosolen, Oliveira \& Bueno, 2015). Around the world, uncontrolled exploitation is damaging ecosystem services that depend on wetlands (Verones, Bartl, Pfister, Vilchez \& Hellweg, 2012).

In the Cerrado region - the world's most threatened savanna environment and Brazil's last remaining agricultural frontier areas under native vegetation - the pronounced seasonality necessitates the use of extensive irrigation for expanding agricultural land use (Rodrigues et al., 2018). This biome is characterized by long dry periods and by the presence of herbaceous plants and scattered woody plants and trees that cover welldrained lateritic soils of low fertility. The Cerrado's wetlands represent islands of natural water storage. In the southeast portion of the ecosystem, our study area in this research, the water dynamic and volume are closely related to rainfall seasonality and the fluctuation of shallow groundwater, comprising a freshwater system integrated with rivers in the catchments. Surrounding the study area, large farms with center-pivot irrigation systems have been using the wetland's water for grain cultivation. Although the allocation of water is legally required by some farmers, the resource's conservation is jeopardized by a lack of knowledge about the balance between input and output of water in wetlands, and about the hydrological dynamic between aquifers and soils with hydromorphic properties. Despite closed wetlands store water and promote groundwater infiltration, influencing the hydrologic cycle at the watershed scale, few studies have relied on field data to further our understanding of the impacts, either individual or cumulative, of natural landscape characteristics and wetland drainage at the local scale (Haque \& Badiou, 2018).

Hydrodynamic models typically partition rainfall into: soil moisture storage, groundwater recharge and surface runoff. This partitioning largely depends not only on the hydrological conditions, but also on the pedogeological conditions. Invasive data acquisition techniques such as drilling or trench excavations are labor-intensive, costly and involve extensive fieldwork sampling and laboratory analysis. They can be efficiently complemented by non-invasive geophysical and remote sensing methods which are time and cost effective, i.e. they succeed in covering large areas of land cheaper and quicker than the soil sampling techniques.

Unmanned Aerial Vehicles (UAVs), and in particular micro-UAVs (payload less than 1.5-2 kg), represent the latest frontier in land and water monitoring because of low-altitude flight and flexible payload design (Anderson and Gaston, 2013). In recent years, miniaturized components (GNSS receivers, inertial measurement units, autopilots) have advanced (Watts et al., 2012), and UAVs have been used also for a wide range of hydrological applications such as fluvial monitoring; river bathymetry and photogrammetric DEM generation using very high resolution (VHR) imagery (Lejot et al., 2007).

Innovative quantification techniques that use remote sensing, and especially those using high spatial-temporal resolution imagery, have been applied in non-invasive mapping of soil surface furthering our understanding of the relationship between surface soil water and aquifer in wetlands (Lin, 2012). In this sense, UAVs equipped with digital cameras had the capability to acquire VHR and describe the distribution of soil moisture in wetlands.

Traditional techniques emphasized in pedological studies (e.g., grain size analysis, mineralogy, chemical, etc.) carried out in a few meters thick do not provide adequate information about soil-water relationships as well the possibility to quantify the volume of water in soil. The use of images generated by UAVs allow obtain information not only from surface features but also to provide excellent estimated values of, e.g., the water volume that the wetland can storage.

Another technique is electrical resistivity tomography (ERT), which can be successfully applied in waterlogged areas, since it is highly sensitive to the presence of water and can provide valuable information regarding the structure and volume of storage in rocks and soils (Carrara, Pece \& Robertini, 1994; Zhang et al, 2016; Luo et al., 2019). These techniques have been widely applied in resource exploration and hydrogeology surveys, having the advantage of being rapid and cost-effective means of generating information (Kearey \& Brooks, 1991; Helaly, 2017). 
Besides, geophysical ERT technique allow to assess soil architecture, from surface to saprolite, highlighting zones with distinctive presence of water in pore space. That information is a key to understand the soil itself; soil-water transfers and to provide a model of water flow and hydrological process.

Aerial imaging is a widely applied technique in the study of wetlands, but digital aerial photogrammetry, i.e., the calculation trough UAVs images of the area and the potential volume of water that can be stocked in the wetlands is a lack of knowledge that requires more discussion, so that is one of our propositions in this work. Still, the second aim of this work is to propose an empirical model for estimating the spatial distribution of water in a specific Cerrado wetland of Minas Gerais state, Brazil, using UAV and ERT techniques to assess groundwater flow and aquifer recharge.

Combining both, UAV and ERT techniques, we employed noninvasively tools to directly quantify soil architecture and hydrodynamic. The methodological choice aimed to improve the needed linkage between digital architecture soil mapping with hydropedology (Lin, 2012).

\section{Materials and Methods}

\subsection{Study site}

The studied area is located in the upper basin of the Rio Claro $\left(19^{\circ} 28^{\prime} 08^{\prime \prime} \mathrm{S}, 47^{\circ} 48^{\prime} 20^{\prime \prime} \mathrm{W}\right)$, at an altitude of 966 $\mathrm{m}$ a.s.l (above sea level), in the municipality of Uberaba-MG (Figure 1). The wetland is a distinct, upstream depression on a flat plateau, occupying a shallow concavity covered with grassy savanna vegetation on hydric soil; it forms the first headwater of the Rio Claro River. The seasonally flooded area extends over 426,064.80 $\mathrm{m}^{2}$. On the flat plateau, the upland soils are well-drained ferruginous concretionary soils (Ferralsols by IUSS, 2014), which have been planted with soybean, corn, and sugarcane crops since the 1970s. This wetland formation corresponds to a topographic depression, the soils of which developed in an aquic moisture regime (Gleysol by IUSS, 2014). The wetland areas have been drastically reduced by agricultural land conversion. Distinct original vegetation covers both Ferralsol and Gleysol soils; the Ferralsols are covered by tree savanna. Wetlands are a grass-dominated ecosystem, with scattered woody plants and small trees covering mounds (locally known asmurundus ), a microtopographic characteristic of the landscape. Mounds are found exclusive in the waterlogged area, up to the border the plateau. The entire area is part of the Cerrado, which has been developed as an agricultural frontier and is becoming a biodiversity extinction hotspot (Anache, Flanagan \& Srivastava, 2018). The climate is characterized by a pronounced dry season in the winter, from April to October, followed by a rainy season during the summer months, from November to March. The average annual rainfall and temperature are $1,516 \mathrm{~mm}$ and $23^{\circ} \mathrm{C}$, respectively. Geologically, the area is characterized by upper Cretaceous sandstones, with iron-rich silt and clay layers belonging to the Serra da Galga Member of the Marília Formation (Fernandes \& Ribeiro, 2015). The catchment has gentle slopes (declivity < $5 \%$ ) and a flat, wide and imperfectly drained valley.

\subsection{UAV Very High Resolution imagery acquisition and processing}

Wetlands are difficult features to map from the ground because of the complexity of the landscape, especially during months when they are flooded. In order to map a wetland with accuracy it is necessary to use an aerial perspective (orthogonal projection, angle of $90^{\circ}$ ), preferably three dimensional and combined with field experiments to fully understanding the character and spatial extent of this phenomenon (Madden et al., 2015). Considering the hydrodynamic characterization of the wetland surface, we used remote sensing and geoprocessing tools in the study area, including photogrammetry by Unmanned Aerial Vehicle (UAV) very high resolution (VHR) images, providing satisfactory results for the calculation of the area and the volume of water that the wetland could, theoretically, store.

The images were obtained with fixed-wing UAV: model eBee Plus RTK/PPK; wingspan $110 \mathrm{~cm}$; weight $1.1 \mathrm{~kg}$; powered by electricity; radio link range $3 \mathrm{~km}$; cruising speed 40-110 km/h (24.8-68.3 mph); wind resistance up to $45 \mathrm{~km} / \mathrm{h}(72.45 \mathrm{mph})$; maximum flight time 50 minutes, with no need for ground control points (GCP) in real-time kinematic (RTK) or post-processed kinematic (PPK) mode; and absolute and relative accuracy of X, Y, Z coordinates (RTK-/-PPK) of up to $3 \mathrm{~cm}$, with a flight altitude of 120 meters. 
For imaging, we used the optical sensor RGB SenseFly S.O.D.A. (Sensor Optimised for Drone Applications), with 20 megapixels.

The flight plan and the correction of the images in PPK mode were done in Emotion Software 3.0, by SenseFly (Figure $2 \mathrm{~A}$ ). The predicted cross-flight lateral and longitudinal overlap was $70 \%$, ensuring high data accuracy by obtaining a large number of images and covering the target with overlaps in two different directions (d'Oleire-Oltmanns, Marzolff, Peter \& Ries, 2012), resulting in better digital surface models (DSM) for the relief analysis. During processing, we were able to overlap an average of nine images of the area where photogrammetry was performed (Figure 2 B).

Next, we performed planialtimetric correction using GNSS data installed in the field during flyovers, which allowed us to obtain post-processing through the Precise Point Positioning service of the Brazilian Institute of Geography and Statistics (IBGE-PPP, www.ibge.gov.br). This operation performs a correction to PPP mode using GPS RINEX (Receiver Independent Exchange Format) data (Matsuoka, de Azambuja, Souza \& Veronez, 2009). Our fieldwork equipment was the GNSS Topcon Hiper PRO RTK (GPS/GLONASS dual receiver), used only for the base unit in operation for 04 hours of point recording. The rover unit was onboard eBee Plus RTK/PPK (Figure 3).

The coordinates corrected by GNSS have significantly greater accuracy than the conventional GPS onboard the UAV. The PPK processing greatly increased the model's reliability, resulting in a precision of $0.038 \mathrm{~m}$, against $6.220 \mathrm{~m}$ with the common GPS (Table 1).

The last step was to process all aerial photographs and GNSS data in the Agisoft Metashape software and perform the digital photogrammetry. This computational operation aligned all the images, creating an orthomosaic. Processing proceeded with the tie point step (generated 5.716 points), followed by the generation of dense cloud (15.699.250 points) and the creation of the 3D model (1.046.616 faces). The digital surface model $(6677 \times 5328)$ and the orthomosaic $(19623 \times 16048)$ were then processed and readied for classification. Finally, after the classification of image data, the contours of the wetland's compartments were created (shapefile) and their area and volume calculated. In order to identify each compartment of the wetland, the digital surface model and the orthomosaic data were processed in a GIS platform. The processing consisted in tests of percentage declivity of the surface and by visual interpretation of the relief. Thus, the Minimum bounding geometry, Erase, Multipart to singlepart and dissolve tools were applied to define the exact declivity of the murundus, which enabled the differentiation of three declivity-density distinct compartments.

To calculate the volume, Agisoft Metashape performs interpolation and value integration using the Best Fit Plane (BFP) tool, by the generation of a plane between each of the compartments and the calculation of the volume below that plane. The plane is generated from automatic analysis of the topographic perimeter profiles of the compartments (Figure 4). The generated plane minimizes the root mean square (RMS) of the orthogonal distance between each vertex of its polygon.

Considering that soil saturation and the elevation of the water level above the land surface occur first in the center of the topographic depression and the cumulative saturation increases towards the border, we used the Best Fit Plane tool to establish an average water height limit for each compartment based in field observations, in order to produce a more reliable volume estimate.

The vegetation does not influence the estimated volume considerably, since wetlands consist largely of grassy area. Therefore, it was not necessary to generate a digital terrain model; a digital surface model was adequate for all calculations. The volume of each compartment is directly influenced by the elevations of the perimeter, by the number of mounds, and by the terrain's unique morphology. In order to subtract the space occupied by the mounds it was necessary to quantify them. The processing is performed through the slope classes that better represented the murundus contour of the study area. Percentage slope tests were performed with indices of $10 \%, 15 \%, 20 \%$ and $25 \%$. The slope index that came closest to the correct mapping was $20 \%$.

\subsection{Electrical resistivity tomography (ERT) 2D and pseudo-3D}

The geophysical surveys were designed to provide the best possible understanding of subsurface hydrody- 
namics, i.e., groundwater behavior and infiltration zone architecture. This technique is rarely applied in wetlands because the equipment is difficult to install in the field (long power cables and batteries). Therefore, electrical tomography was performed to estimate the flow direction of groundwater, showing the direction of the superficial water flow and a horizontal infiltration pattern in the center of the concavity (compartment $3)$.

The ERT technique involves the DC Resistivity method for geophysical acquisition data, measuring the electric resistivity parameter using electrodes fixed on the surface of the ground, connected to the measuring instrument by cable assembly (Keller \& Frischknecht, 1966; Telford, Geldart \& Sheriff, 2004).

The data was acquired using the Schlumberger arrangement, with $2 \mathrm{~m}$ between each iron electrode. We assembled nine 80-meter lines in the direction $\mathrm{N} 45^{\circ} \mathrm{W}$, spaced 10 meters apart, and one 80-m line perpendicular to all the others (Figure 5).

For data acquisition, we used the Terrameter LS (ABEM Instrument, Sweden), which can measure resistivity from a single pre-programmed module for transmitting and receiving automated signals, with $250 \mathrm{~W}, 1 \mu \mathrm{V}$ resolution, and a maximum current of $2.5 \mathrm{~A}$ (ABEM 2012). This equipment was calibrated to the following specifications: transmission of $200 \mathrm{~mA}$ for $1 \mathrm{~s}$ for each measurement. During acquisition, the data were stored in the equipment's internal memory, then exported via USB interface as DAT file format compatible with the input format of word processing software.

The data were processed and manipulated to obtain a two-dimensional electrical profile and three-dimensional models of resistivity $(\Omega . \mathrm{m})$. All data were processed in the Res2Dinv software, which automatically performs the following tasks: (1) determining a two-dimensional (2D) model of resistivity of the subsurface, using data obtained through electrical imaging surveys (Griffiths \& Barker, 1993); (2) quickly generating 2D inversion models for DC Resistivity, using the algorithm of smoothness constrained least-square method; and (3) performing topographic modeling when reversing the data set, which incorporates the topography within the mesh model (Geotomo Software 2003). The topographic data was corrected by the GNSS in field.

The Geotomo Software applies the smooth inversion method, which is the mathematical method of least squares that uses the optimization Gauss-Newton and quasi-Newton, described by Loke \& Barker (1996). This method is based on cells; the software recognizes the terrain surface as rectangular blocks, with constant values for each parameter studied (DeGroot-Hedlin \& Constable, 1990). The results are 2D models of inversion of resistivity data, based on distance (length of the acquisition lines) and depth, and presented in logarithmic graphic scale and intervals of color interpolation values.

The numeric data of the 2D inversion for each compartment were assembled in a single spreadsheet, compiling the positions of readings along the lines (variable $\mathrm{x}$ ), spacing between the lines (variable $\mathrm{y}$ ), depth modeled by inversion (variable $\mathrm{z}$ ), and the value of electrical resistivity $(\mathrm{R})$, which is subsequently used to generate the pseudo-3D visualization models. A pseudo-3D model is a method used for rendering visual-data with a sense of depth ( $\mathrm{Z}$ axis).

The pseudo-3D model was processed in the Oasis Montaj platform, where the 2D data obtained in the Res2Dinv software were interpolated using the minimum curvature method to generate pseudo-3D visualization models. The models can be visualized as layers, according to the chosen depth.

Visualization of pseudo-3D models generated from geophysical data contributes to our understanding of complex geological structures and hydrological problems. This methodology has many environmental applications and is described in other studies (Moreira et al., 2012, 2016a, b, 2017, 2018; Veloso, Moreira \& Cortes, 2015; Cortes, Moreira \& Veloso, 2016; Vieira et al. 2016; Helene, Moreira \& Carrazza, 2016; Carrazza, Moreira \& Helene, 2016).

\section{Results and Discussion}

3.1 Potential of UAV imagery to study soil moisture and stock of water in wetland 
The selection of the modeling approach depends, besides the modelling objectives, on both scientific and technical aspects as well as on the resources available, which include the scale of the simulation domain, topography, hydrological and topographical data available and the complexity of the hydraulic regime (Wester et al., 2018). For these reasons, to estimate water storage the studied wetland was subdivided into three compartments, in order to facilitate the hydrodynamic modeling. The compartments were defined through rigorous analysis of the images (RGB and DMS) generated by UAV, which showed distinct pixel-information about soil surface inside that vary according topography. Thus, we considered the topography and terrain morphology: the slope, from the border to the center of the topographic depression that characterizes the wetland site, and the density of the microtopography (mound fields), which is directly related to the level of hydromorphism in the wetland (Rosolen et al., 2019).

Between the border and the center of the depression, compartment 1 corresponds to its boundary with the well-drained plateau; compartment 2 is the intermediate segment between compartments 1 (boundary) and 3 (center); and compartment 3 corresponds to the central part of the topographic depression (Figure $2 \mathrm{C}$ ).

The data acquired by the UAV images allowed us to estimate the amount of water that each compartment can support and, therefore, the total water volume that can be stored on the surface of the studied wetland. Based on the data of the altitude, geographical location and the slope in relation to adjacent points of each pixel of the images we calculated the volume by delineating a 3D polygon in each compartment. Because the mounds (murundus) do not fill up with water, their volumes were subtracted from the total volume of the compartments.

The result of semi-automatic extraction through slope and visual interpretation of the orthomosaic obtained 1751 mounds features in the research area. The biggest mound have $3643.40 \mathrm{~m}^{2}$ and the smallest mapped shape was $1.01 \mathrm{~m}^{2}$. Regarding the perimeter recorded in the extraction, the smallest recorded form was 4.60 $\mathrm{m}$ and the largest with $476.63 \mathrm{~m}$. Figure 6 shows the histograms with murundus distribution by area and perimeter in the research area. It is observed that the murundus of the research area are mostly distributed with perimeters ranging from $24.48 \mathrm{~m}$ to $58.49 \mathrm{~m}$ and the area are distributed mostly between $67.41 \mathrm{~m}^{2}$ and $167.37 \mathrm{~m}^{2}$.

When each compartment is flooded, it displays a distinct water residence time and dynamic associated with its topographic position. Water flooding over the land surface reaches compartment 1, during the rainfalls. In compartment 3 the water level remains high for a prolonged period due the lateral water influx from compartment 2 and 1. Clearly, there are variation in soil moisture pattern linked to topography, and that variable has a major impact on the hydrology in landscape (Moore et al., 1991). The largest amount of microtopography with little trees and shrubs on their top occurs in Compartment 1 in agreement with lower soil moisture. Wetland area also exhibit grassy cover in Compartment 3 in agreement with the elevated soil moisture. These differences of soil moisture observed in field are in accordance to features observed in the aerial imaging.

Rainfall seasonality determines the wetland's water supply. In the field, we observed that the wetland area is a natural seasonal water reservoir, filling up in rainy months and drying up during dry months (Figure 7 A, B). We performed the photogrammetry at dry months in order to estimate the water stock during the rainy period.

Table 2 shows each compartment's total storage capacity, in cubic meters and liters (Figure 2 D), its area in square meters, and the minimum and maximum altitudes that were used in the calculations. The altitude values were calculated for each pixel of the images of each compartment.

In compartment 3, we conducted the electrical tomography tests to provide an understanding of subsurface hydrodynamics and identify the architecture of soil and rock, which acts as an infiltration zone.

\subsection{Water flow paths by using $2 D$ and pseudo-3D ERT data}

An overall analysis of all electrical tomography data allowed the definition of a single scale of values, facilitating comparisons between the sections. For the electrical resistivity data, we defined a variable scale 
between $200 \mathrm{~m}$ and $10000 \mathrm{~m}$, the lower and higher values measured during the field data acquisition. The definition of these values enabled the distinction of low-resistivity zones (cool colors) and high-resistivity zones (hot colors) in the 2D lines and pseudo-3D maps.

The images representing the inversion of electrical resistivity data (Figure 8) show subsurface heterogeneity; the low resistivity values may be associated with groundwater (blue colors), and in contrast, the high resistivity (dark green, brown and red colors) values suggest the presence of dry soil (Keller \& Frischknecht 1966; Telford et al. 2004; Loke, 2004). In the analysis of the studied wetland, low values of resistivity ranged from 200 to $612 \mathrm{.m}$; intermediate values from 1069 to $1870 \mathrm{~m}$; and high values of resistivity from 1870 to 10000 .m.

All ten lines showed clear contrasts in resistivity values, with both low and high values. Lines $2,3,4,5,7$ and 10 best represent the wetland contrasts (Figure 8).

Stretches of lines 5 and 10, which ran perpendicular to each other, were located exactly in the lower topographic level of compartment 3 of the wetland. In these stretches, low-resistivity zones (blue colors) are visible immediately below the soil surface, reaching the deep aquifer. These zones are where surface water interacts with the groundwater and the aquifer recharge occurs (McLachlan, Chambers, Uhlemann \& Binley, 2018). Similar features having low resistivity show a lateral continuity in the distribution of the aquifer and are present in all parallel lines. Deeper in the regolith, just below the low-resistivity features (6-8 meters depth), lay sharply contrasting zones of high-resistivity features (dark green), indicating a barrier to vertical water flow. At this level, saprolite rock supports the aquifer and imposes a lateral continuity of the water body. In the soil mantle and saprolite, layers of increased saturation lead to more lateral hydraulic conductivity (Appels et al., 2015). The dense and fine-textured layers in the bedrock and soil mantle retain the water flow (Freer et al., 2002). Such stratification is typical in the Serra da Galga Formation (Fernandes \& Ribeiro, 2015).

The aquifer is shallow, because the low-resistivity zones begin at two meters deep (964 m.a.s.l.). However, the aquifer has a vertical extension of at least 12 meters in some places, which is most visible in the lines $2,3,4$ and 5 . This demonstrates a connection between shallow subsurface water and aquifer-water, in a genuine interaction.

Zones with intermediate values (1069-1870 .m) (light green) present features that suggest transition zones, where water may be contained in soil porosity, indicating that the aquifer is not confined. The fine soil texture occurring here can also retain water and shows lower resistivity (Greer et al., 2017).

The physical parameter of electrical conductivity is a response from the water content or the contents and composition of the soil and rock solutions. When rocks are saturated, the electrical conductivity of the solutions usually increases, decreasing the electrical resistivity values. Various studies indicate a positive relationship between electrical conductivity and both porosity and hydraulic conductivity of an aquifer; i.e. , low resistivity reflects higher porosity and higher hydraulic conductivity (Kelly, 1977; Kelly \& Frohlich, 1985; Urish, 1981; Chandra, Ahmed, Ram \& Dewandel, 2008; Chukwudi, 2011; Moreira, Cavalheiro, Pereira \& Sardinha, 2013).

High-resistivity zones in the central region (values between 1870 and $5719 \Omega$.m) are a common feature of all lines and indicate the presence of low-permeability materials, with no significant presence of stored water.

Generally, the most superficial portions of the soil (0 to 2 meters deep) present high-resistivity zones, sometimes throughout their entire extent, such as in line 7 . This occurs due to the presence of very clayey soils with low hydraulic conductivity, making the studied wetland an excellent natural reservoir.

In order to enhance the visualization and understanding of groundwater behavior, pseudo-3D models were produced by interpolation of data generated by the 2D inversion of electric tomography lines.

From the pseudo-3D models, resistivity maps were generated for every two meters of depth, from $966 \mathrm{~m}$ a.s.l. (Surface) to $950 \mathrm{~m}$ a.s.l. (16 meters deep). Thus, nine resistivity maps were generated (Figure 9). 
The map representing the surface (966 $\mathrm{m}$ a.s.l.) shows that the central region has lower resistivity (values below $3270 \Omega . m$ ) than the rest of the map, indicating zones of more permeable soil and, thus, of possible aquifer recharge. At greater depths in the soil mantle, high-resistivity materials are evident in the central region, oriented in the NW-SE direction. Up to 6 meters deep (960 $\mathrm{m}$ a.s.l.), the water seems to flow horizontally, while from 8 meters deep (958 $\mathrm{m}$ a.s.l.), the resistivity in this zone intensifies, causing the water flow to move towards the southwest and, in greater quantity, towards the northeast. Yet, in the southeast region of the maps, the low-resistivity zones continue as the depth increases. This trend suggests that the low and high-resistivity zones must grow closer together at greater depths, indicating that the aquifer is connected.

\subsection{Revealing the integration of soil-aquifer in wetland combining UAV-ERT tools}

Based on a joint analysis of the surface geoprocessing and on our understanding of the groundwater dynamics, we were able to ascertain the occurrence of a lateral water flow from compartment 1 that is, theoretically, responsible for prolonged flooding in compartment 3. Hillslope with saturated flow dominates lateral flow and reflects the relative contribution to the lateral hydraulic potential gradient of the relief of the lower-most impermeable boundary (Harman \& Kim, 2019). During wet periods, for instance, when water tables are close to the surface, shallow subsurface flow can occur (Brannen, Spence, \& Ireson, 2015) due to the formation of an effective transmission zone (van der Kamp \& Hayashi, 2009) (Figure 10).

In the field, we observed that compartment 3 remains flooded for the longest period. This observation, in addition to the analysis of the electrical resistivity tomography, justifies the hypothesis that direct aquifer recharge occurs in this compartment.

In the area, the soil water has been supplied by rainfall concentrated during the summer seasons (OctoberMarch). In the end of that period, the water level remains over the land surface conducting to long-term soil saturation characterizing a typical wetlands hydrology. That conditions are accept when the water table is within $30 \mathrm{~cm}$ of soil surface or above the surface for period of 14 days or more in a year (Vepraskas and Lindbo, 2012). The studied wetland is not connected with any river by surficial channel, imposing the vertical flows towards the shallow aquifer. That dynamic characterizes the hydrology in the topographic depression where surface (water that enter in soil by rain) and subsurface (shallow aquifer) waters are mixed. The soils in catena allow the direct recharge of aquifer although the occurrence of subsurface massive layers with higher bulk density could diminish the velocity of vertical flow. That layer has light grey color, in the ERT sections, due to iron-depletion and is continuous in the entire extension of the catena.

Combining soil morphology and ERT images made it possible to propose a broader hydrologic interpretation on wetland on the plateau. On the plateau, the topographic depression that characterize wetlands with aquic soils are zones of aquifer recharge characterized by preferential downward movement of water from periodically unsaturated soil surface to saturated groundwater. The vertical flows occurred by the opening of leakage point in the center of the depression (compartment 3) which was formed by geochemical erosion, particularly the iron-depletion from soil matrices. The contemporary hydrology in the wetland is a result of soil landscape changes closed linked to its past geological history. The flat plateau is a remnant of South American Surface and the landform was preserved by the presence of continuous ferricrete. Regional environmental changes to more humid climatic conditions (Salgado-Laboriau et al., 1998) enhanced the leaching of iron from the oxidized phase in the ferricrete opening soft zones that act as preferential flows path to water. The chemical process (deferrugination) is followed by loss of pedality resulting in topographic lowering (Lucas and Chauvel, (1992), Antonellini et al., 2019). The topographic depression developed in flat surfaces retains water inducing to endosaturation of soils (Vepraskas and Lindbo, 2012), which induces the rejuvenation of the old lateritic materials. Ferricrete developed in lateritic soils is an impermeable layer that can retains rainwater over in a pershed watertable on the highest positions of the landscape (Tardy, 1993). The excess of water in top soil intensify ferricrete dissolution opening permeable points through which the soil water percolates deep in the profile reaching the shallow aquifer characterizing a recharge zone by leaching and redox depletions (Evans and Freeland, 2000). That soil-water process corresponds to the contemporaneously hydrology in the wetland developed in the plateau. 


\section{Conclusion}

The study aimed to test the efficacy of remote sensing and geophysical techniques to quantify and understand the water cycle in a savanna wetland of Brazil. ERT and the digital aerial photogrammetry from RGB sensors aboard UAV are non-destructive techniques for assessing water cycling in wetlands and can be used to identify, quantify and promote the protection of water resources. The studied wetland is a depressed area in a well-drained lateritic environment in the Cerrado biome, surrounded by agricultural areas. The wetland acts as a natural seasonal rainwater reservoir, storing up to $416.996,3 \mathrm{~m}^{3}$ of water on the land surface during the rainy months. The distinct internal compartments that characterize the wetland morphology present distinct water storage. Furthermore, water is retained in soil porosity, feeding the aquifer by vertical flow and permeable and impermeable layers in soil and rock characterize the complex hydrology of this environment. Surface water and aquifer are connected in the center of the wetland through direct vertical flow, whereas the subsurface heterogeneity interrupts the flow direction, driving the water laterally and expanding the flooded area. Remotely sensed VHR images allied with geophysical techniques allowed complete surface and subsurface imaging and offered visual tools that significantly contribute to understanding hydrodynamics of the wetland. Further studies will be focused on assessing water use conflict between wetland water storage and agricultural consumption.

\section{Acknowledgement}

This work was financially supported by the FAPESP - Fundação de Amparo à Pesquisa do Estado de São Paulo (Processes n 2017/14168-1) and by the CNPq - Conselho Nacional de Desenvolvimento Científico e Tecnológico.

\section{Data Availability Statement}

The data that support the findings of this study are available from the corresponding author upon reasonable request.

\section{References}

ABEM, A. (2012). Terrameter LS Instruction Manual.

ANA - Nacional Agency of Water. (2017). Usos da Água. In: Relatório Conjuntura Brasil - Recursos Hídricos. Agência Nacional de Águas-Ministério do Meio Ambiente (MMA),

Brasilia (DF). 51- 86.

Anache, J. A., Flanagan, D. C., Srivastava, A., \& Wendland, E. C. (2018). Land use and climate change impacts on runoff and soil erosion at the hillslope scale in the Brazilian Cerrado. Science of the Total Environment , 622, 140-151.

ANDERSON, Karen; GASTON, Kevin J. Lightweight unmanned aerial vehicles will revolutionize spatial ecology. Frontiers in Ecology and the Environment, v. 11, n. 3, p. 138-146, 2013.

Antonellini, M., Giambastiani, B.M.S., Greggio, N., Bonzi, L., Calabrese, L., Luciani, P., Perini, L., Severi, PP., 2019. Processes governing natural land subsidence in the shallow coastal aquifer of the Ravenna coast, Italy. Catena 172, 76-86.

Appels, W.M., Graham, C.B., Freer, J.E., McDonnell, J.J. (2015). Factors affecting the spatial pattern of bedrock groundwater recharge at the hillslope scale. Hydrological

Processes , 29, 4594-4610.

Brannen, R., Spence, C., \& Ireson, A. (2015). Influence of shallow groundwater-surface water interactions on the hydrological connectivity and water budget of a wetland complex. Hydrological Processes , 29(18), $3862-3877$. 
Carrara, E., Pece, R., \& Roberti, N. (1994). Geoelectrical and seismic prospections in hydrogeology: model and master curves for the evaluation of porosity and water saturation. Pure and Applied Geophysics , 143(4), 729-751.

Carrazza, L. P., Moreira, C. A., \& Helene, L. P. I. (2016). Gully cavity identification through electrical resistivity tomography.Revista Brasileira de Geofísica , 34(2), 241- 250.

Chandra, S., Ahmed, S., Ram, A., \& Dewandel, B. (2008). Estimation of hard rockaquifers hydraulic conductivity from geoelectrical measurements: a theoretical development with field application. Journal of Hydrology , 357(3-4), 218-227.

Chukwudi, C. E. (2011). Geoelectrical studies for estimating aquifer hydraulic properties in Enugu State, Nigeria. International Journal of Physical Sciences , 6(14), 3319-3329.

deGroot-Hedlin, C., \& Constable, S. (1990). Occam's inversion to generate smooth, two- dimensional models from magnetotelluric data. Geophysics , 55(12), 1613-1624.

d'Oleire-Oltmanns, S., Marzolff, I., Peter, K. D., \& Ries, J. B. (2012). Unmanned aerial vehicle (UAV) for monitoring soil erosion in Morocco. Remote Sensing , 4(11), 3390-3416.

Evans, C.V., Freeland, J.A., 2000. Wetland soils of basins and depressions of glacial terrains. In: Richardson, J.L., Vepraskas, M.J. (Eds.), Wetland Soils: Their Genesis, Morphology, Hydrology, Landscapes, and Classification. CRC Press, Boca Raton, FL, pp. 251-266.

FAO - Food and Agriculture Organization of the United Nations. (2016). AQUASTAT website, Land and Water Division. Website accessed on 2018/12/10.

Fernandes, L. A., \& Ribeiro, C. M. M. (2015). Evolution and palaeoenvironment of the Bauru Basin (Upper Cretaceous, Brazil).Journal of South American Earth Sciences ,61,

71-90.

Freer, J., McDonnell, J. J., Beven, K. J., Peters, N. E., Burns, D. A., Hooper, R. P., Kendall, C. (2002). The role of bedrock topography on subsurface storm flow. Water Resources Research , 38(12), 5-1.

Greer, B.M., Burbey, T.J., Zipper, C.E., Hester, E.T. (2017). Electrical resistivity imaging of hydrologic flow through surface coal mine valley fills with comparison to other landforms. Hydrological Processes, $31: 2244-2260$.

Geotomo Software. (2003). Res2Dinv (v.3.54) for 98/ME/2000/ NT/XP. Geoelectrical Imaging 2D and 3D.

Griffiths, D. H., \& Barker, R. D. (1993). Two-dimensional resistivity imaging and modelling in areas of complex geology. Journal of Applied Geophysics , 29(3-4), 211-226.

Haque, A., Ali, G., \& Badiou, P. (2018). Hydrological dynamics of prairie pothole wetlands: Dominant processes and landscape controls under contrasted conditions. Hydrological Processes , 32(15), 2405-2422.

Harman, C. J., \& Kim, M. (2019). A low-dimensional model of bedrock weathering and lateral flow coevolution in hillslopes: 1. Hydraulic theory of reactive transport. Hydrological Processes , 33, 466-475.

Helaly, A. S. (2017). Assessment of groundwater potentiality using geophysical techniques in Wadi Allaqi basin, Eastern Desert, Egypt-Case stuldy. NRIAG Journal of Astronomy and Geophysics, 6(2), 408-421.

Helene, L. P. I., Moreira, C. A., \& Carrazza, L. P. (2016). Applied geophysics on a soil contaminated site by chromium of a tannery in Motuca (SP). Brazilian Journal of Geophysics , 34 (3), 309-317.

Junk, W. J., Piedade, M. T. F., Lourival, R., Wittmann, F., Kandus, P., Lacerda, L. D., .\& Schongart, J. (2013). Brazilian wetlands: their definition, delineation, and classification for research, sustainable management, and protection. Aquatic Conservation: Marine and Freshwater Ecosystems, 24(1), 5-22.

Kearey, P., Brooks, M., \& Hill, I. (1991). An introduction to geophysical exploration. John Wiley \& Sons. 
Kelly, W. E. (1977). Geoelectric sounding for estimating aquifer hydraulic conductivity. Groundwater , $15(6), 420-425$.

Kelly, W. E., \& Frohlich, R. K. (1985). Relations between aquifer electrical and hydraulic properties. Groundwater, 23(2), 182-189.

Keller, G. V., \& Frischknecht, F. C. (1966). Electrical methods in geophysical prospecting. Pergamon Press, Inc.

LEJOT, Jerome et al. Very high spatial resolution imagery for channel bathymetry and topography from an unmanned mapping controlled platform. Earth Surface Processes and Landforms: The Journal of the British Geomorphological Research Group, v. 32, n. 11, p. 1705-1725, 2007.

Lin, H. (2012). Understanding soil architecture and its functional manifestation across scales. In Lin, H. (Ed.), Hydropedology: Synergistic Integration of Soil Science and Hydrology Hydropedology(pp. 41-74), Walthan:MA, Academic Press.

Loke, M. H., \& Barker, R. D. (1996). Rapid least-squares inversion of apparent resistivity pseudosections. In 56th EAEG Meeting.

Loke, M. H. (2004). Tutorial: 2-D and 3-D electrical imaging surveys.

Lucas, Y., Chauvel, A., 1992. Soil formation in tropically weathered terrains. In: Butt, C.R.M., Zeegers, H. (Eds.), Handbook on Exploration Geochemistry, Regolith Exploration Geochemistry in Tropical and Subtropical Terrains. Elsevier, Amsterdan, pp. 57-77.

Luo, W., Xu, X., Liu, W., Liu, M., Li, Z., Peng, T., .. \& Zhang, R. (2019). UAV based soil moisture remote sensing in a karst mountainous catchment. Catena, 174, 478-489.

Madden, M., Jordan, T., Bernardes, S., Cotten, D. L., O'Hare, N., \& Pasqua, A. (2015). Unmanned Aerial Systems and Structure from Motion Revolutionize Wetlands Mapping. Remote sensing of wetlands: Applications and advances, 195.

Matsuoka, M. T., de Azambuja, J. L. F., de Souza, S. F., \& Veronez, M. R. (2009). Potencialidades do servico on-line de Posicionamento por Ponto Preciso (CSRS-PPP) em aplicacoes geodesicas. Gaea-Journal of Geoscience , 5(1), 42-48.

McLachlan, P.J., Chambers, J.E., Uhlemann, S.S., Binley, A. (2018). Geophysical characterisation of the groundwater-surface water interface. Advances in Water Resources 109, 302-319.

Millington, N. (2018). Producing water scarcity in Sao Paulo, Brazil: The 2014-2015 water crisis and the binding politics of infrastructure. Political Geography , 65, 26-34.

Moore, I.D., Grayson, R.B., Ladson, A.R., 1991. Digital terrain modelling: a review of hydrological, geomorphological, and biological applications. Hydrol. Process. 5, 3-30.

Moreira, C. A., Lopes, S. M., Schweig, C., \& da Rosa Seixas, A. (2012). Geoelectrical prospection of disseminated sulfide mineral occurrences in Camaqua sedimentary basin, Rio Grande do Sul state, Brazil. Brazilian Journal of Geophysics , 30 (2).

Moreira, C. A., Cavalheiro, M. L. D., Pereira, A. M., \& Sardinha, D. D. S. (2013). Analise das relacoes entre parametros geoletricos e vazoes para o aquifero livre de Cacapava do Sul-RS. Aguas Subterraneas , 45-59.

Moreira, C. A., Reis, S. S., Malagutti Filho, W., \& Hansen, M. A. F. (2016). Geoelectric modeling of supergenic manganese ocurrence in heliodora region, Southern Minas Gerais. Brazilian Journal of Geophysics , 34 (3), 299-308.

Moreira, C. A., Borsatto, K., Ilha, L. M., Santos, S. F. D., \& Rosa, F. T. G. (2016). Geophysical modeling in gold deposit through DC Resistivity and Induced Polarization methods. REM - International Engineering Journal , 69(3), 293-299. 
Moreira, C. A., Carrara, A., Helene, L. P. I., Hansen, M. A., Malagutti Filho, W., \& Dourado, J. C. (2017). Electrical resistivity tomography (ERT) applied in the detection of inorganic contaminants in suspended aquifer in Leme city (Brazil). Brazilian Journal of Geophysics , 35 (3), 213-225.

Moreira, C. A., Paes, R. A. S., Ilha, L. M., \& da Cruz Bittencourt, J. (2018). Reassessment of Copper Mineral Occurrence Through Electrical Tomography and Pseudo 3D Modeling in Camaqua Sedimentary Basin, Southern Brazil. Pure and Applied Geophysics , 1-14.

Rodriguez, R. D. G., Scanlon, B. R., King, C. W., Scarpare, F. V., Xavier, A. C., \& Pruski, F. F. (2018). Biofuel-water-land nexus in the last agricultural frontier region of the Brazilian Cerrado.Applied Energy , $231,1330-1345$.

Rosolen, V., de Oliveira, D. A., \& Bueno, G. T. (2015). Vereda and Murundu wetlands and changes in Brazilian environmental laws: challenges to conservation. Wetlands Ecology and Management, 23(2), 285292.

Rosolen, V., Bueno, G. T., Mutema, M., Moreira, C. A., Junior, I. R. F., Nogueira, G., \& Chaplot, V. (2019). On the link between soil hydromorphy and geomorphological development in the Cerrado (Brazil) wetlands. Catena, 176, 197-208.

Telford, W. M., Telford, W. M., Geldart, L. P., Sheriff, R. E., \& Sheriff, R. E. (2004). Applied geophysics. Cambridge university press.

Tardy, Y., 1993. Petrologie des laterites et des sols tropicaux. Masson, Paris.

Urish, D. W. (1981). Electrical resistivity-hydraulic conductivity relationships in glacial outwash aquifers. Water Resources Research , 17(5), 1401-1408.

van der Kamp, G., \& Hayashi, M. (2009). Groundwater-wetland ecosystem interaction in the semiarid glaciated plains of North America.Hydrogeology Journal , 17(1), 203-214.

Vepraskas, M.J., Lindbo, D.L., 2012. Redoximorphic features as related to soil hydrology and hydric soils. In: Lin, H. (Ed.),Hydropedology: Synergistic Integration of Soil Science and Hydrology. Academic Press, USA, pp. 143-172.

Verones, F., Bartl, K., Pfister, S., Jimenez Vilchez, R., \& Hellweg, S. (2012). Modeling the local biodiversity impacts of agricultural water use: case study of a wetland in the coastal arid area of Peru. Environmental science \& technology , 46(9), 4966-4974.

Vieira, L. B., Moreira, C. A., Cortes, A. R., \& Luvizotto, G. L. (2016). Geophysical modeling of the manganese deposit for Induced Polarization method in Itapira (Brazil). Geofisica Internacional,55(2), 107117.

Watts Adam C.; Ambrosia, Vincent G.; Hinkley, Everett A. Unmanned aircraft systems in remote sensing and scientific research: Classification and considerations of use. Remote Sensing, v. 4, n. 6, p. 1671-1692, 2012.

Wester, S. J., Grimson, R., Minotti, P. G., Booij, M. J., \& Brugnach, M. (2018). Hydrodynamic modelling of a tidal delta wetland using an enhanced quasi-2D model. Journal of hydrology , 559 , 315-326.

Zhang, G., Zhang, G. B., Chen, C. C., Chang, P. Y., Wang, T. P., Yen, H. Y., .. \& \& Jia, Z. Y. (2016). Imaging rainfall infiltration processes with the time-lapse electrical resistivity imaging method. Pure and Applied Geophysics, 173(6), 2227-2239.

Table 1 - Coordinates correction from GPS to GNSS. RTK (Real Time Kinematic) error of $6.220 \mathrm{~m}$ and PPK (Post Processed Kinematic) error of 0,038 m.

\begin{tabular}{llll}
\hline \multicolumn{4}{l}{ Geotags (GPS) } \\
\hline RTK & 0 & $0 \%$ & $\sigma=0,000 \mathrm{~m}$
\end{tabular}




\begin{tabular}{llll}
\hline & Geotags (GPS) \\
\hline Standalone & 204 & $100 \%$ & $\sigma=6.220 \mathrm{~m}$ \\
Overall & 204 & $100 \%$ & $\sigma=6.220 \mathrm{~m}$ \\
& & Geotags (GNSS) & \\
PPK & 204 & $100 \%$ & $\sigma=0.038 \mathrm{~m}$ \\
Standalone & 0 & $0 \%$ & $\sigma=0.000 \mathrm{~m}$ \\
Overall & 204 & $100 \%$ & $\sigma=0.038 \mathrm{~m}$ \\
\hline
\end{tabular}

Table 2 - Volume, area and minimum and maximum altitudes of internal wetland compartments 1,2 and 3.

\begin{tabular}{lllll}
\hline & Compartment 1 & Compartment 2 & Compartment 3 & Total \\
\hline Volume $\left(\mathrm{m}^{\mathbf{3}}\right)$ & $313.121,00$ & $85.923,20$ & $17.952,10$ & $416.996,3$ \\
Volume $\left(\mathrm{Liters}^{2}\right)$ & $313.121,000$ & $85.923,200$ & $17.952,100$ & $416.996,300$ \\
Area $\left(\mathrm{m}^{\mathbf{2}}\right)$ & $141.239,30$ & $150.481,20$ & $134.344,30$ & $426.064,8$ \\
Max. Altitude & 976.39 & 974.91 & 973.01 & - \\
$(\mathrm{m})$ & & & & - \\
$\begin{array}{l}\text { Min. Altitude } \\
(\mathrm{m})\end{array}$ & 968.7 & 968.7 & 968.7 & \\
\hline
\end{tabular}

Figure legends

Figure 1 - Geographic location of the studied wetland.

Figure 2 - (A) Predicted cross-flight performed in the field by the UAV for image acquisition. B) Graphic showing the spatial overlap of the images, indicating high overlap in the region of interest (average of 9 longitudinally and laterally overlapping images). (C) Compartmentalization identified through aerial image processing: from border to center, compartments 1, 2 and 3. (D) Volume of stored water, in cubic meters, calculated for each compartment. In compartment 3 , the water level remains higher for a longer period.

Figure 3 - Description of eBee Plus RTK/PPK UAV, and GNSS (base) support mode.

Figure 4 - Topographic profile of the perimeter of each compartment, used by the software to define the best fit plane, a plane that limits the polygon and calculates the area and volume of water that each compartment can store.

Figure 5 - Position of the electrical tomography (ERT) lines in the study area.

Figure 6 - Histogram with mounds distribution by (A) perimeter (B) and area.

Figure 7 - Field observations of rainfall seasonality. (A) August 2018, the month with the lowest precipitation, when compartment 3 was dried up. (B) December 2018, the month with the highest precipitation, when compartment 3 was already flooded.

Figure 8 - Inversion models of resistivity for the high-contrast sections of the set obtained in the field. The dashed line marks the areas of low resistivity (aquifer), indicating its spatial disposition. The arrows indicate the water flow, which migrates from vertical to lateral in the subsurface.

Figure 9 - Maps of resistivity between the shallower and deeper positions of investigation. Dashed lines indicate the location of horizontal infiltration (recharge zone of the aquifer) and flow change (lower resistivity as the depth increases). 
Figure 10 - Schematic model of the wetland surface and subsurface hydrodynamic during the dry and rainy seasons.

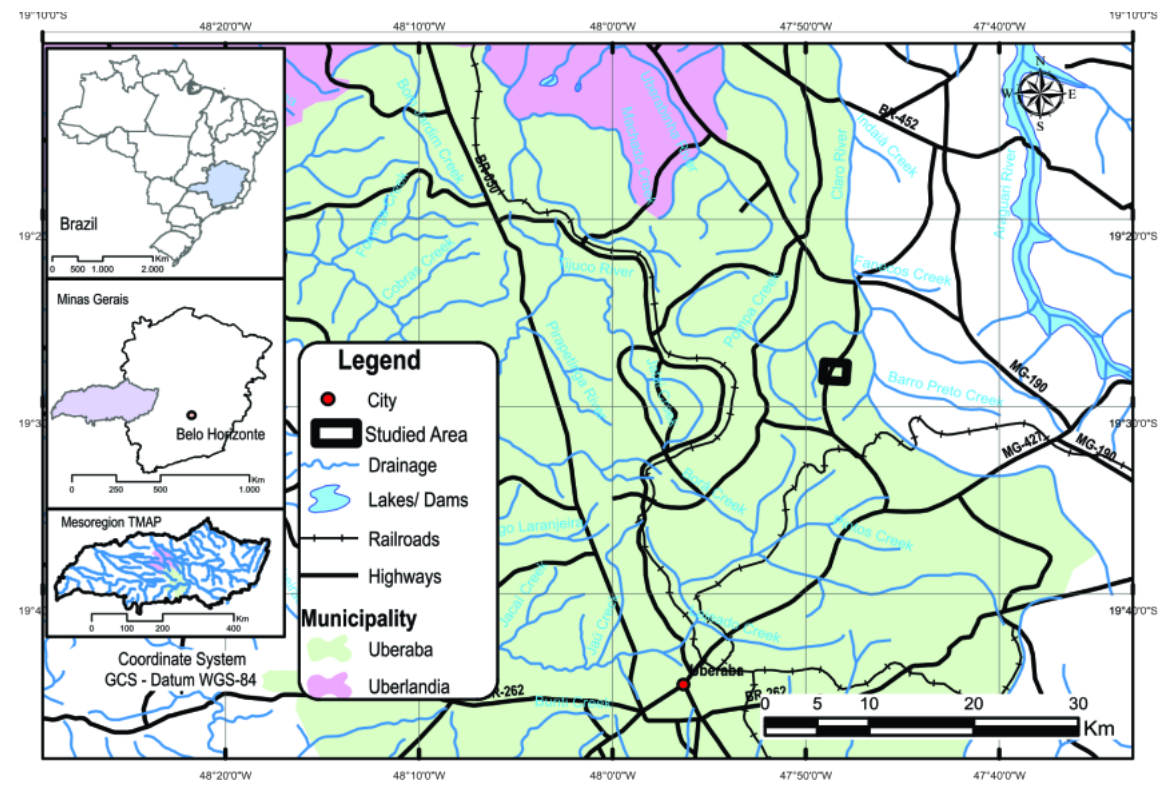



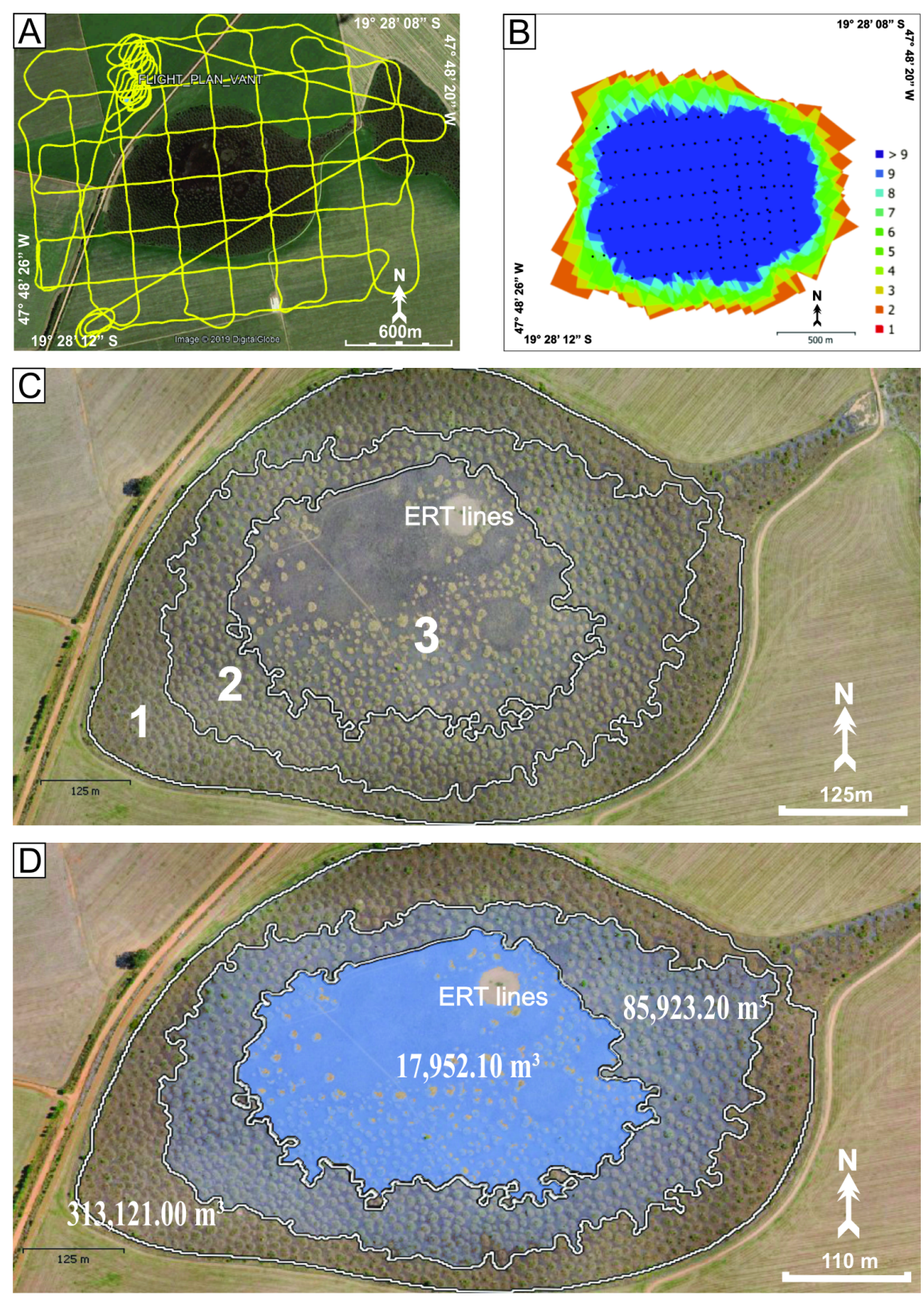

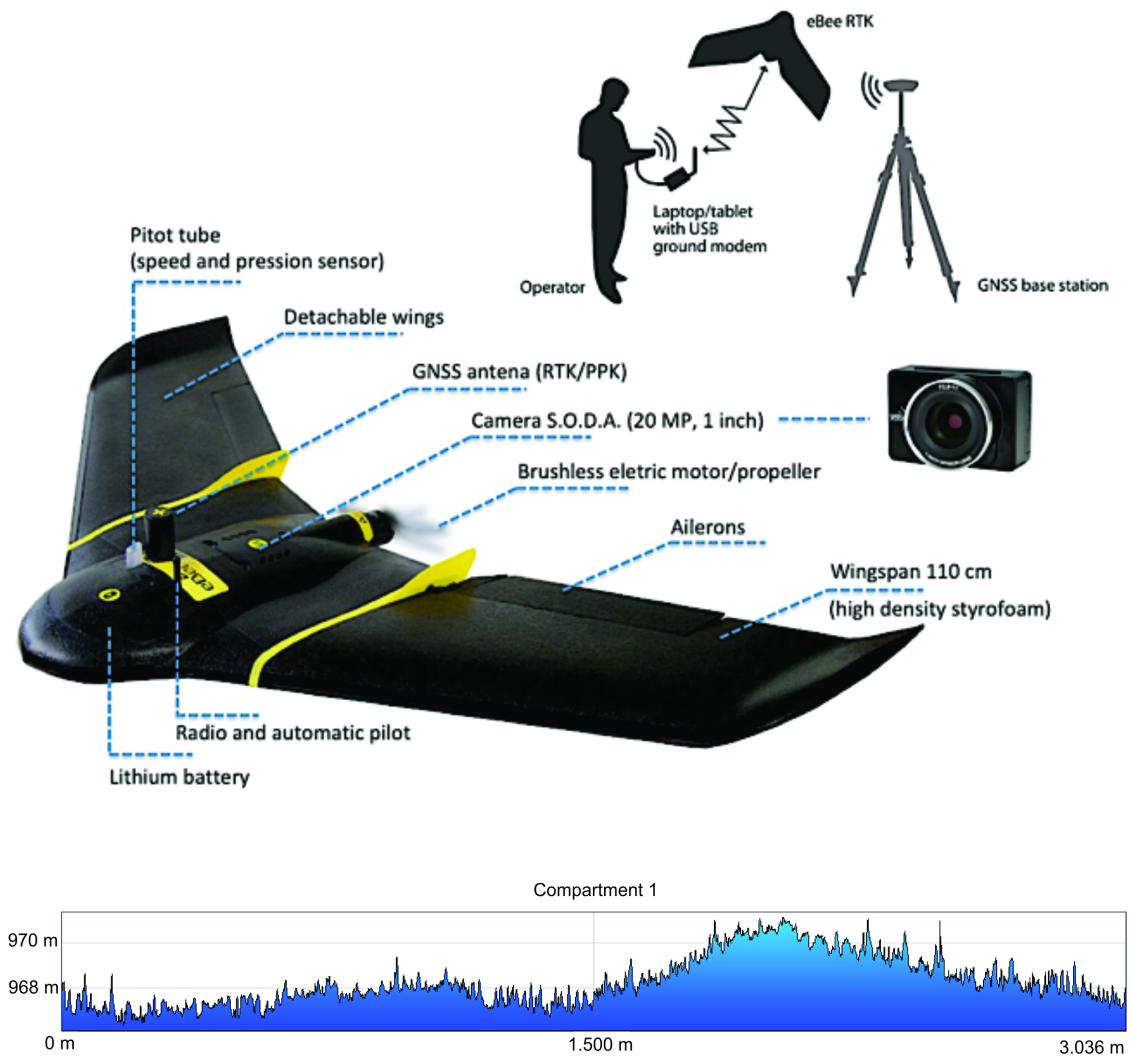

Compartment 2

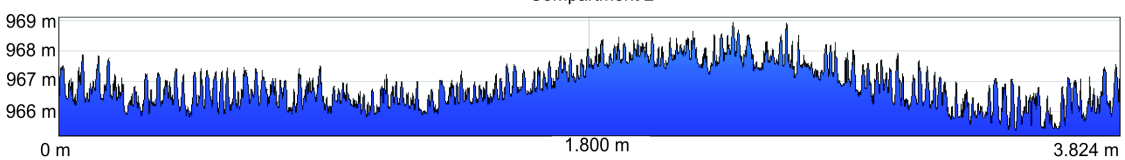

Compartment 3

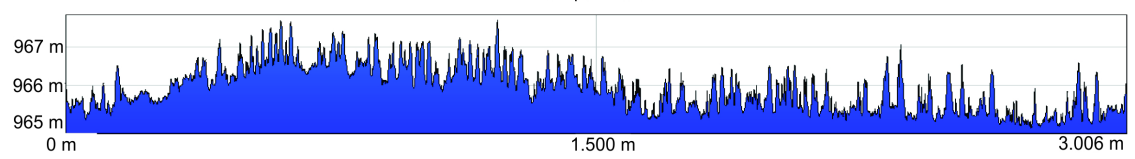



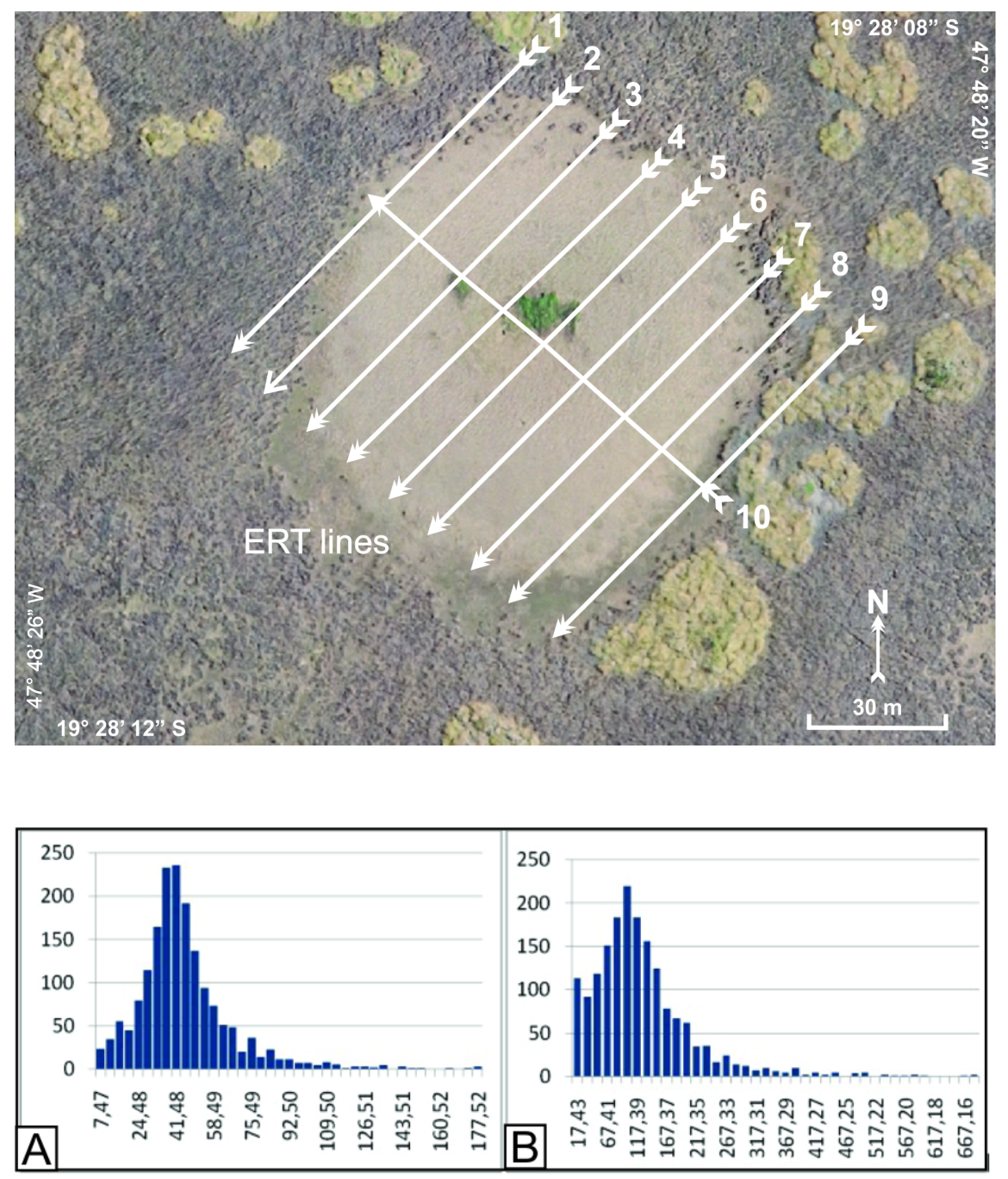


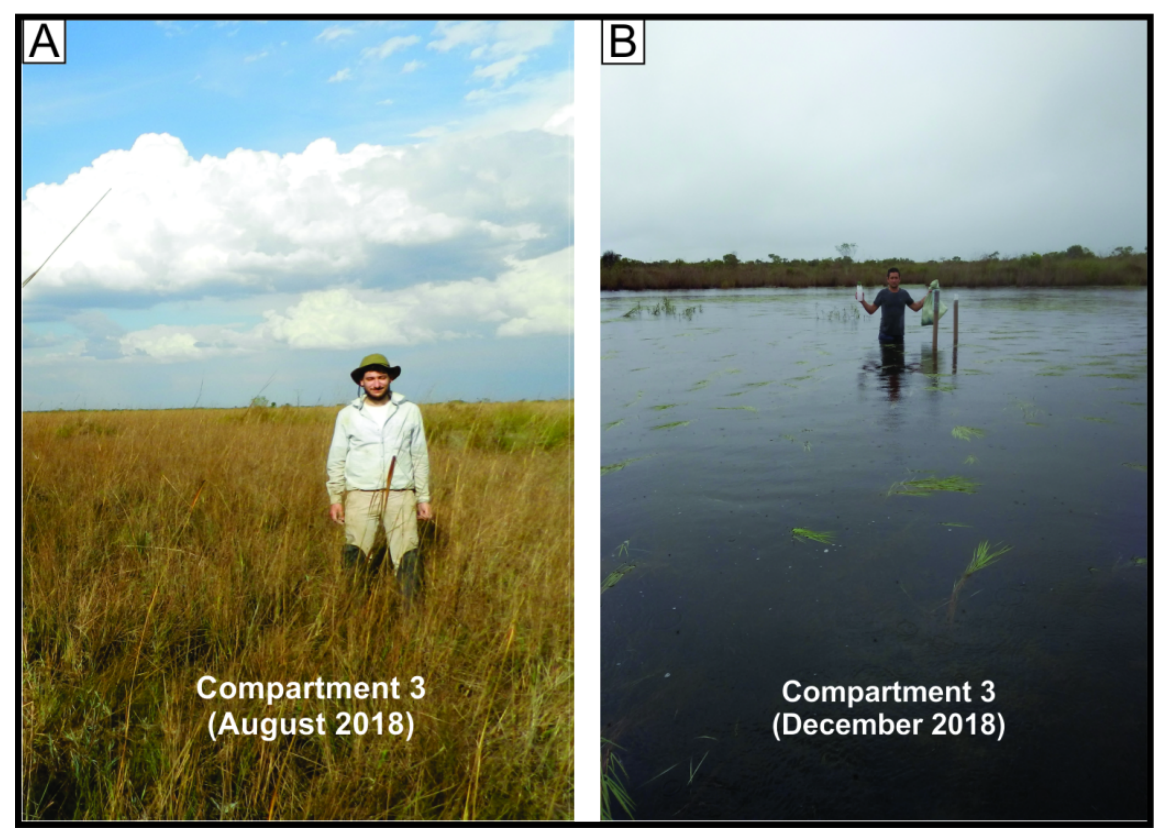




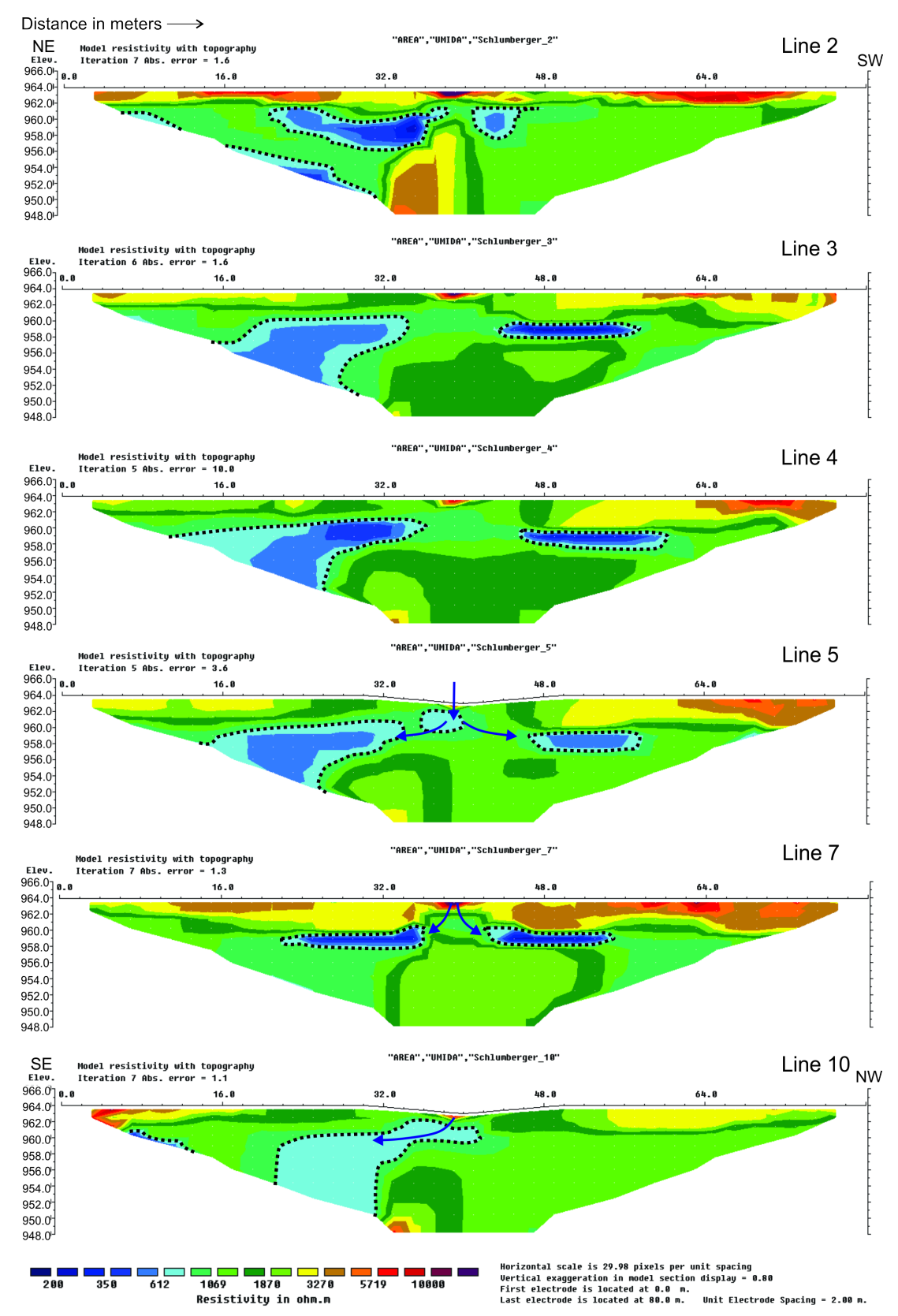



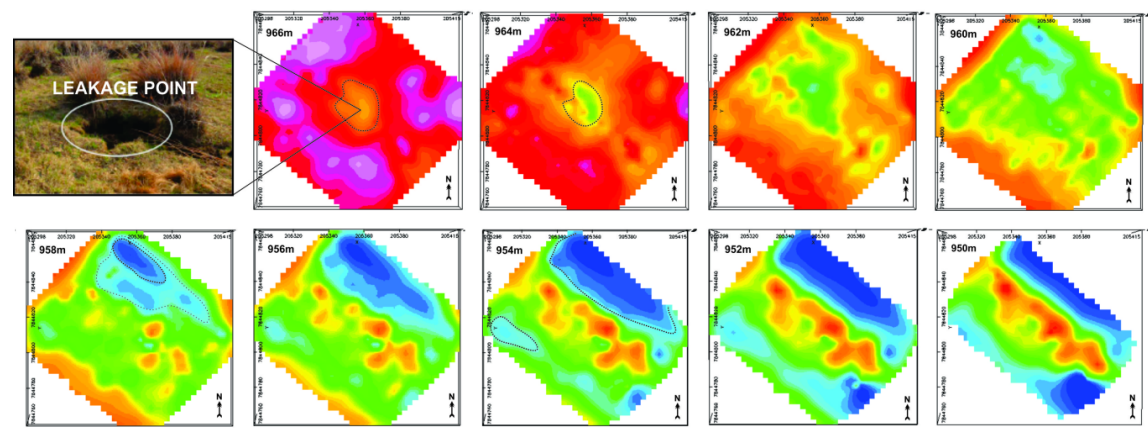

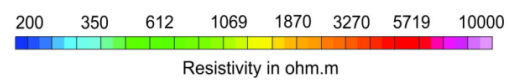
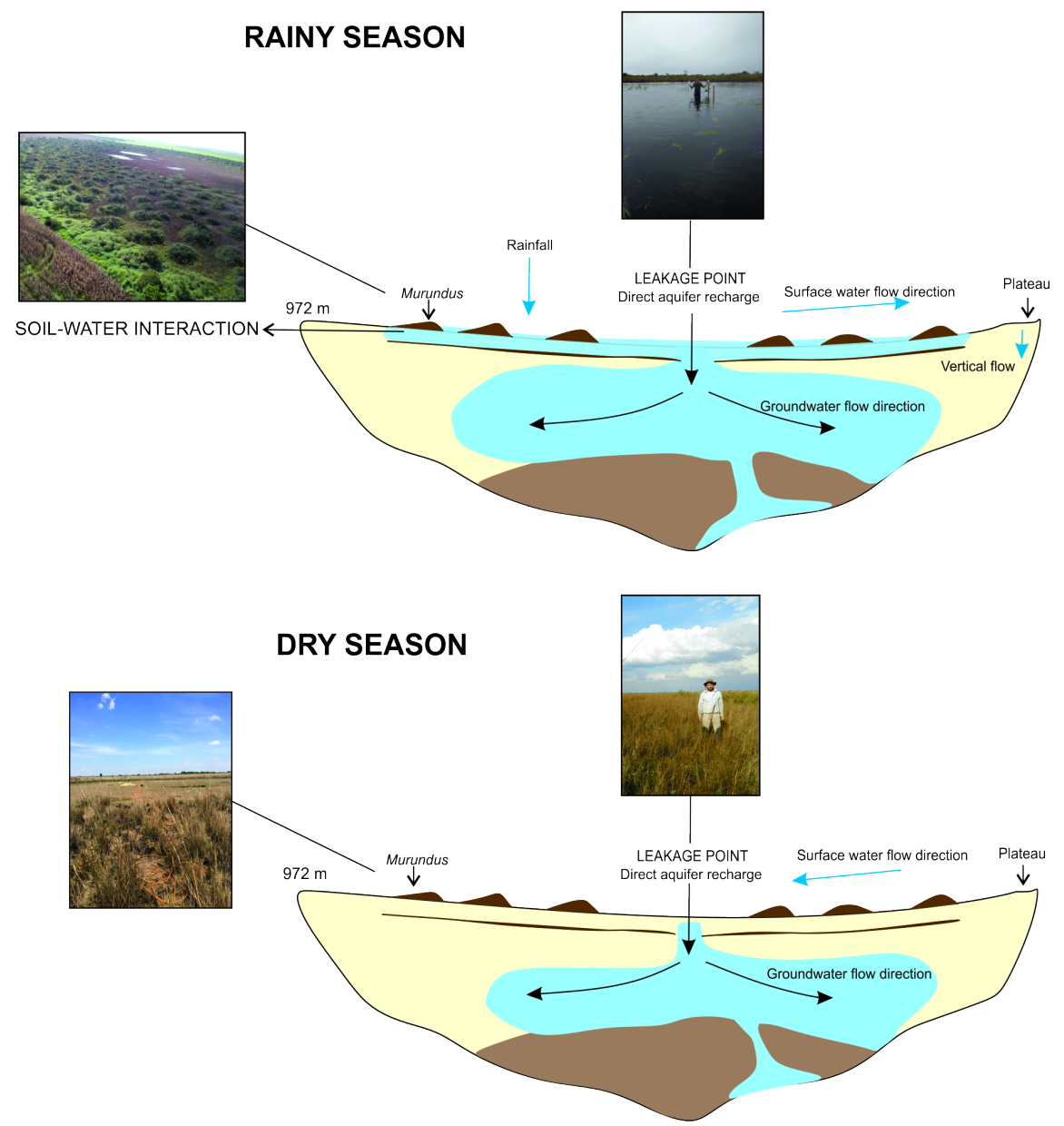